\title{
Radiographic and Histomorphometric Evaluation of Biomaterials Used for Lateral Sinus Augmentation: A Systematic Review on the Effect of Residual Bone Height and Vertical Graft Size on New Bone Formation and Graft Shrinkage
}

\author{
Paolo Pesce ${ }^{1, *(\mathbb{D})}$, Maria Menini ${ }^{1}\left(\mathbb{D}\right.$, Luigi Canullo ${ }^{2} \mathbb{D}$, Shahnawaz Khijmatgar ${ }^{3}\left(\mathbb{D}\right.$, Laura Modenese ${ }^{1}$, \\ Gianmarco Gallifante ${ }^{1}$ and Massimo Del Fabbro ${ }^{3,4}$ (D) \\ 1 Department of Surgical Sciences (DISC), University of Genoa, Ospedale S. Martino, L. Rosanna Benzi 10, \\ 16132 Genoa, Italy; maria.menini@unige.it (M.M.); modenese.laura@gmail.com (L.M.); \\ gmarco.gallifante@gmail.com (G.G.) \\ 2 Department of Periodontology, University of Bern, 3012 Bern, Switzerland; luigicanullo@yahoo.com \\ 3 Department of Biomedical, Surgical, and Dental Sciences, University of Milan, 20122 Milan, Italy; \\ khijmatgar@gmail.com (S.K.); massimo.delfabbro@unimi.it (M.D.F.) \\ check for \\ updates \\ 4 IRCCS Orthopedic Institute Galeazzi, 20161 Milan, Italy \\ * Correspondence: paolo.pesce@unige.it
}

Citation: Pesce, P.; Menini, M.; Canullo, L.; Khijmatgar, S.; Modenese, L.; Gallifante, G.; Del Fabbro, M. Radiographic and Histomorphometric Evaluation of Biomaterials Used for Lateral Sinus Augmentation: A Systematic Review on the Effect of Residual Bone Height and Vertical Graft Size on New Bone Formation and Graft Shrinkage. J. Clin. Med. 2021, 10, 4996. https:// doi.org/10.3390/jcm10214996

Academic Editor:

Pablo Galindo-Moreno

Received: 25 September 2021

Accepted: 25 October 2021

Published: 27 October 2021

Publisher's Note: MDPI stays neutral with regard to jurisdictional claims in published maps and institutional affiliations.

Copyright: (C) 2021 by the authors Licensee MDPI, Basel, Switzerland. This article is an open access article distributed under the terms and conditions of the Creative Commons Attribution (CC BY) license (https:// creativecommons.org/licenses/by/ $4.0 /)$.

\begin{abstract}
The aim of the present systematic review was to investigate the effect of residual bone height (RBH) and vertical bone gain on new bone formation (NBF) and graft shrinkage after lateral sinus lifts using different biomaterials. Methods: An electronic search was conducted on three databases to identify randomized controlled trials (RCTs) published until January 2021 with at least one follow-up at 6 months and at least five patients treated, comparing biomaterials used for maxillary sinus augmentation with a lateral approach. Graft volumetric changes, RBH, vertical bone gain, implant failure, and post-operative complications were evaluated. The risk of bias was assessed using the Cochrane tool. Results: We used 4010 identified studies, of which 21 were RCTs. Overall, 412 patients and 533 sinuses were evaluated. Only three publications had an overall low risk of bias. After 6 months, xenograft $(X G)$ showed the least volume reduction $(7.30 \pm 15.49 \%)$, while autogenous graft (AU) was the most reabsorbed $(41.71 \pm 12.63 \%)$. NBF appeared to not be directly correlated with $\mathrm{RBH}$; on the contrary, the overall linear regression analysis showed that NBF significantly decreased by $1.6 \%$ for each $\mathrm{mm}$ of postoperative vertical graft gain. This finding suggests that the greater the augmentation, the lower the NBF. A similar tendency, with a regression coefficient even higher than the overall one, was also observed with alloplast (AP) and XG. Conclusions: The present results suggested that NBF was essentially independent of preoperative bone height. On the contrary, the smaller the volume was of the graft placed, the higher the amount of new bone formed, and the smaller the graft shrinkage was. Minimizing the augmentation volume might be beneficial to graft healing and stability especially when using AP and XG.
\end{abstract}

Keywords: sinus lift; bone regeneration; biomaterials; grafts

\section{Introduction}

In the posterior maxilla, where the possible lack and/or low quality of bone associated with the pneumatisation of the sinus represent a risk for implant osseointegration [1-3], the implant rehabilitation is often combined with regenerative procedures such as a lateral or transcrestal maxillary sinus augmentation [4-7].

In 1978, Tatum was the first to practise bone grafting under the sinus membrane [8], and in 1980, Boyne and James performed the first lateral maxillary sinus augmentation using the Caldwell-Luc technique [9]. 
Even if biological complications occur with this technique [10,11], standard length implants can be used, as opposed to short implants, to increase the bone-implant interface, improve primary stability, and reduce implant failure [12,13]. Although alternative rehabilitation strategies have been proposed such as the use of tilted implants [14,15], the successful combination of sinus augmentation and standard implant placement has been strongly supported in the scientific literature. In 1996, Jensen et al. reported a success rate of $90 \%$ three years post-loading [16]. Similar or better results have been reported by several subsequent studies and systematic reviews [17-20].

As an alternative to autogenous bone graft $(\mathrm{AB})$, several biomaterials such as allograft $(A G)$, xenograft $(X G)$, and alloplastic material (AP), either alone or in combination, have been proposed as grafting materials for sinus lifts [21]. While osteoconductive properties characterize $\mathrm{AG}, \mathrm{XG}$, and $\mathrm{AP}$, autogenous bone is the only graft material presenting an osteoinductive and osteogenic capacity [22]. For these reasons, the use of $\mathrm{AB}$ is still considered the gold standard even though it can lead to post-operative complications at the donor site and is associated with greater morbility, limited availability, and significant resorption [23]. While the use of only $\mathrm{AB}$ in maxillary sinus lifts guarantees a high implant survival rate $[16,18]$, the autograft is often mixed with slowly resorbing materials such as XG [24].

XG has demonstrated its effectiveness in maxillary sinus floor augmentation, both alone and combined with $\mathrm{AB}$ [25-27]. XGs are good space-makers and very slowly resorbable biomaterials. Histological studies have reported the presence of intact xenograft particles, 3-11 years post-sinus lift (SL), showing no significant dimensional changes, as compared to those observed six months after surgery [28,29].

Alloplastic materials such as polymers, calcium sulphates, hydroxyapatite (HA), calcium phosphates, and bioactive glass are inorganic osteoconductive bone substitutes [23,24]. An histomorphometric study comparing an AG (composed of freeze-dried bone allograft (FDBA)) and an AP (composed of biphasic calcium phosphate (BCP)) proved that the use of an AG determines similar new bone formation and a reduced amount of residual graft with respect to $\mathrm{AP}$, concluding that the latter is less osteoconductive [30].

Demineralized, freeze-dried bone allograft (DFDBA) and FDBA are space-occupying osteoconductive biomaterials that have only slight osteoinductive properties [31,32]. In addition, various samples of DFDBA from different bone banks may have dissimilar potentiality to promote new bone formation, depending on the donor's age, as demonstrated by Schwartz et al. [33].

Several recent reviews based on histomorphometric data comparing different graft materials used in SL agree on the supremacy of AB to induce new bone formation [34-36], as opposed to other authors such as Trimmel et al. who have supported the use of a composite graft made of XG and bone marrow concentrate (BMC) [37].

The aim of the present review was therefore to analyse the effects of residual bone height $(\mathrm{RBH})$ and vertical bone gain on the new bone formation (NBF) and the graft shrinkage after lateral sinus lifts using different biomaterials. A second aim was to test if the dimensional baseline variables such as the residual bone height and the initial size of the graft may play a role on the shrinkage and the new bone formation.

\section{Materials and Methods}

\subsection{Protocol and Registration}

The present systematic review followed the guidelines of transparent reporting of systematic reviews and meta-analyses (PRISMA), and the protocol was registered on Prospero with the code CRD42020199261.

The following focused questions were analysed in accordance with the PICO strategy:

1. What was the effect of residual bone height and post-operative vertical change on new bone formation in sinus augmentation procedures 6 months after loading?

Population: Healthy patients with an atrophic posterior maxilla requiring lateral sinus augmentation; 
Intervention: Sinus augmentation with any biomaterial;

Comparison: Any comparison between materials included in the intervention or with augmentation without adding biomaterials;

Outcomes: Review of new bone formation, implant survival, and complications.

2. What was the shrinkage of different bone substitutes when used in sinus augmentation procedures 6 months after surgery?

Population: Healthy patients with an atrophic posterior maxilla requiring lateral sinus augmentation;

Intervention: Sinus augmentation with any biomaterial;

Comparison: Any comparison between materials included in the intervention or with augmentation without adding biomaterials;

Outcomes: Graft volumetric changes measured with $\mathrm{CBCT}$, implant survival, and complications.

\subsection{Search Strategy}

The research of the articles was performed online using three main databases: PubMed/ MEDLINE, Scopus, and the Cochrane Central Register of Controlled Clinical Trials (CENTRAL). The investigation began in April 2020 and ended in January 2021. The survey did not exclude any article by year of publication or language and was performed using the following search strategy: "(maxillary sinus lift OR maxillary sinus augmentation OR maxillary sinus elevation OR maxillary sinus grafting OR maxillary sinus surgery OR sinus graft) AND dental implants" that was modified for each database. A by-hand search was also performed in the following journals: the British Dental Journal, the British Journal of Oral and Maxillofacial Surgery, Clinical Implant Dentistry and Related Research, Clinical Oral Implants Research, Clinical Oral Investigations, the European Journal of Oral Sciences, Implant Dentistry, the International Journal of Oral and Maxillofacial Implants, the International Journal of Oral and Maxillofacial Surgery, the International Journal of Oral Implantology (formerly, the European Journal of Oral Implantology), the International Journal of Periodontics and Restorative Dentistry, the Journal of Clinical Periodontology, the Journal of Dental Research, the Journal of Dentistry, the Journal of Maxillofacial and Oral Surgery, the Journal of Oral and Maxillofacial Surgery, the Journal of Periodontal Research, and the Journal of Periodontology.

The reference lists of all identified RCTs and relevant systematic reviews were scanned for any additional studies. Online registries providing information about in-progress clinical trials and the grey literature were checked (http://clinicaltrials.gov/; http:/ /www. centerwatch.com/clinicaltrials/; http:/ / www.clinicalconnection.com/; www.greylit.org; www.opengrey.eu; accessed on 1 October 2021).

\subsection{Eligibility Criteria}

Only randomized controlled trials (RCTs), both split-mouth and parallel, that included a test and a control group or two or more comparisons were included. Only studies in English with at least one post-surgery follow-up at 6 months and at least 5 patients treated were included. Non-randomized clinical studies, case series, pilot studies, retrospective studies, cohort studies, reviews, animal or in vitro studies, and any publications using duplicate data were excluded. Studies using trans-sinus implants and comparing the use of short implants (not associated with the sinus lift technique) with long implants (inserted contextually to the lift) were not considered.

Selection of studies:

Two reviewers (G.G. and L.M.) independently read the titles, the abstracts, and the full texts of the selected articles to ensure they met the inclusion criteria. In cases of disagreement, a third co-author (P.P.) was consulted.

\subsection{Data Extraction}

After the selection of the articles to be included in the review, the data were collected by two authors (L.M. and G.G.) using a Microsoft Excel spreadsheet (Excel 16.4, Microsoft 
CO., Redmond, WA, USA). The following information was extracted: year and journal of publication, authors, title, type of study (parallel or split-mouth), country in which the study was performed, presence of sponsors, number of operators, presence or absence of smoking patients, total number of patients and maxillary sinuses treated and evaluated, age and sex of patients, total number of implants inserted and type (contextual or delayed insertion with the sinus lift), follow-up period in months, outcomes, grafting materials used, use or not of a covering membrane, number of implants inserted in each group, number of failed implants with relative timing, any post-operative complications found, residual vertical bone dimension prior to surgery, volumetric bone gain, and finally, histomorphometric data on the amount of new bone obtained. The biomaterials used in the various studies were reported based on the category they belong to, i.e., autologous graft (AU), xenograft $(\mathrm{XG})$, allograft (AG), alloplastic material (AP), autologous tissue graft (ATG), biological material (BIO), or for spontaneous healing (only membrane elevation) without the use of any material $(\mathrm{SH})$.

If the article contained the total linear measurements before and after surgery, the actual bone gain was calculated by subtracting the preoperatively measured value from the post-operative one; this measure was reported in $\mathrm{mm} \pm \mathrm{SD}$.

For the volumetric measurement, the volume found at least 6 months after surgery was reported in $\mathrm{mm}^{3} \pm \mathrm{SD}$ along with the percentage of contraction with respect to immediate post-surgery graft volume.

In cases of missing or unclear data, the authors of the various articles were contacted by e-mail to obtain further details.

\subsection{Risk of Bias Assessment}

The risk of bias (RoB) assessment was conducted according to the Cochrane criteria, Cochrane Handbook for Systematic Reviews of Interventions [38]. All the different RoB domains were evaluated for each RCT: random sequence generation (selection bias), allocation concealment (selection bias), blinding of participants and personnel (performance bias), blinding of outcome assessment (detection bias), incomplete outcome data (attrition bias), and selective reporting (reporting bias).

If a potential bias could cause a serious weakness of confidence in the results, the associated risk was defined as high. Otherwise, the risk of bias was classified as "low" if it did not alter the results, or as "unclear" if it raised some doubts about the results of the study.

\subsection{Statistical Analysis}

It was planned to undertake a meta-analysis of the graft shrinkage for each comparison between materials if at least three studies with the same comparison were found. However, no meta-analysis could be performed as there were no more than two studies for each type of comparison. Therefore, no meta-analysis was performed. Linear regression analysis was undertaken between outcome variables (NBF, graft shrinkage percentage) and baseline data (RBH, post-surgery graft height). GraphPad Prism 5.1 (GraphPad, La Jolla, CA, USA) was used as the statistical software.

\section{Results}

\subsection{Bibliographic Search and Study Selection}

Figure 1 reports the flowchart of the selection process. The electronic search within the three databases produced a total of 4010 articles, with 2641 obtained from PubMed/ MEDLINE, 1090 from Scopus, and 279 from the Cochrane Central Register of Controlled Clinical Trials (CENTRAL). After removing 661 duplicates, 3349 articles were analysed. Following the reading of the titles and the abstracts, 3135 were excluded; the remaining 214 were examined using the full text. This research phase excluded 193 articles because they did not comply with the eligibility criteria and made it possible to include a total of 
21 publications [39-59]. Reasons for exclusion are reported in Supplementary Table S1 and Figure 1.

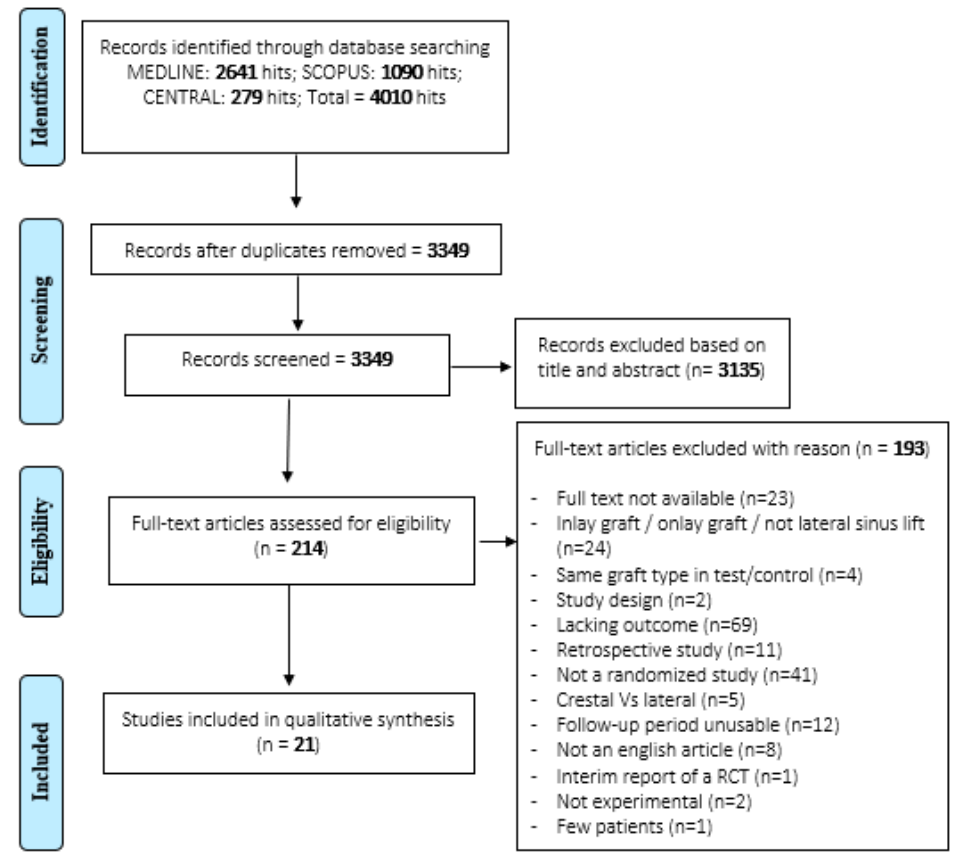

Figure 1. Flowchart of the included studies.

To obtain some missing information, the authors of 10 articles were contacted $[39,41,43-45,54,56-59]$. Unfortunately, only three of them replied.

\subsection{Description of Included Studies}

The 21 articles included in the review presented a comparison among at least two different biomaterials: 8 of them were parallel studies [41,45,47,48,50,54,55,57], 11 splitmouths [39,40,42-44,49,51,52,56,57,59], and 2 presented both modalities [46,53].

Most of the publications were not sponsored, and only six articles were financed $[40,45,46,49,50,54]$.

In total, 412 patients and 533 sinuses were analysed with 319 for the first PICO question and 301 for the second one. In 12 studies, smokers were excluded from the patient's selection $[39,40,42-46,53-55,57,58]$ while the other 10 articles included smoking patients in the sample.

Four studies presented a population with a mean age below 50 years [45,49,50], 11 between 50 and 60 years [40,41,43,47,48,52,53,55,57-59], and 2 had patients with a mean age of more than 60 years $[44,56]$. In three studies, the age was reported only as the median value as 55 years $[47,51]$ and 50.5 years [39]. In another two articles, the ranges are included as between 40-77 [46] and 45-62 years [42]. One study did not report this data [54].

In only two studies, the implant insertion was performed simultaneously with the lateral sinus lift procedure [41,48]; in 11 other studies, the implants were inserted at the secondary surgical stage 6 months later $[39,43,45,47,49,53,56-59]$. In a study by Panagiotou et al. [52], the fixtures were inserted 8 months after sinus lift; in that of de Lange et al. [44], between 3 and 8 months (average time of 6 months), and in those of Chackartchi et al. [40] and Lorenz et al. [51], between 5 and 9 months. Only the study by Lee et al. [50] did not specify the timing of implant insertion.

While in most RCTs, the surgical procedure involved the use of a resorbable membrane covering the lateral window, three studies did not consider their use [48,56,59], and two did not specify it [43,54]. Finally, an article described the use of a biological glue in one group, and the same glue was added with autologous PLT concentrates (APCs) in another [39]. 
Histomorphometrical and vertical height data were reported by 13 studies, including 5 studies that compared different types of heterologous grafts $[40,43,50,52,53], 1$ that utilized two different homologous bone [41] while 2 studies compared alloplastic materials with each other $[45,47]$. The remaining RCTs compare, instead, $\mathrm{AU}+\mathrm{PC}$ against $\mathrm{AG}+\mathrm{XG}$ + PC [48], AU against AU + PC [39], AU and AP [59], XG and AP [44], and, finally, XG juxtaposed with XG + PC [56]. In general, AG was employed in 34 sinuses, $X G$ in $81, A P$ in 109, $\mathrm{AU}$ in 21, $\mathrm{AU}+\mathrm{PC}$ in 28, $\mathrm{AU}+\mathrm{XG}+\mathrm{PC}$ in 15, XG + PC in 5, and finally, XG + AP in 6.

Volumetric changes were considered in 11 articles. Three studies compared the use of alloplastic material with autologous bone and/or their combination $[49,54]$ while another 2 studies compared two different materials from the same family including one that utilized alloplastic grafts [47] while the other used heterologous [50]. The remaining RCTs compared: AG with AG + XG [55], AP with XG [51], AU with AG [58], XG with AG [57], $\mathrm{AU}$ with $\mathrm{XG}+\mathrm{AU}$ [42] and, finally, XG + AP with XG [53]. Altogether, AU was used in 49 sinuses, $\mathrm{AU}+\mathrm{AP}$ in 17, AP in 105, AG in 47, AG + XG in 17, XG in 50, XG + AU in 10, and finally, XG + AP in 6 sinuses.

Nine studies did not specify the number of implants placed after the lateral sinus lift $[40,42,45,49,50,52-54,56]$ while one declared to have inserted $2-5$ textures in the site without further clarification [39]. One author did not report the insertion of implants [46]. In all other studies, 620 implants were inserted: 55 in sinus grafted with AU, 111 with XG, 160 with AP, 205 with AG, 28 with $\mathrm{AU}+\mathrm{PC}, 31$ with $\mathrm{AU}+\mathrm{XG}+\mathrm{PC}$, and, finally, 30 with $\mathrm{AG}+\mathrm{XG}$. Table S2.

The main characteristics of the included studies are summarized in Supplementary

\subsection{Risk of Bias}

The evaluation of the risk of bias (RoB) of the included studies (Figure 2) showed that three of them had a low $\operatorname{RoB}[50,53,56]$. Four studies were considered at unclear risk for selection bias-random sequence $[43,45,55,58]$ and one at high risk [59] while, for allocation concealment, ten had an unclear $\operatorname{RoB}[39,40,42-45,47,49,51,54]$ and six, a high risk $[41,46,48,55,57,59]$. When estimating the risk associated with the blindness of participants and staff (i.e., performance bias), two studies were unclear [57,59], and two with high RoB $[41,52]$ were highlighted. The evaluation of the detection bias revealed the presence of five studies classified as unclear [40,41,54,55,59] and two as high [44,57]. Finally, about attrition and reporting bias, all studies had low risk. 


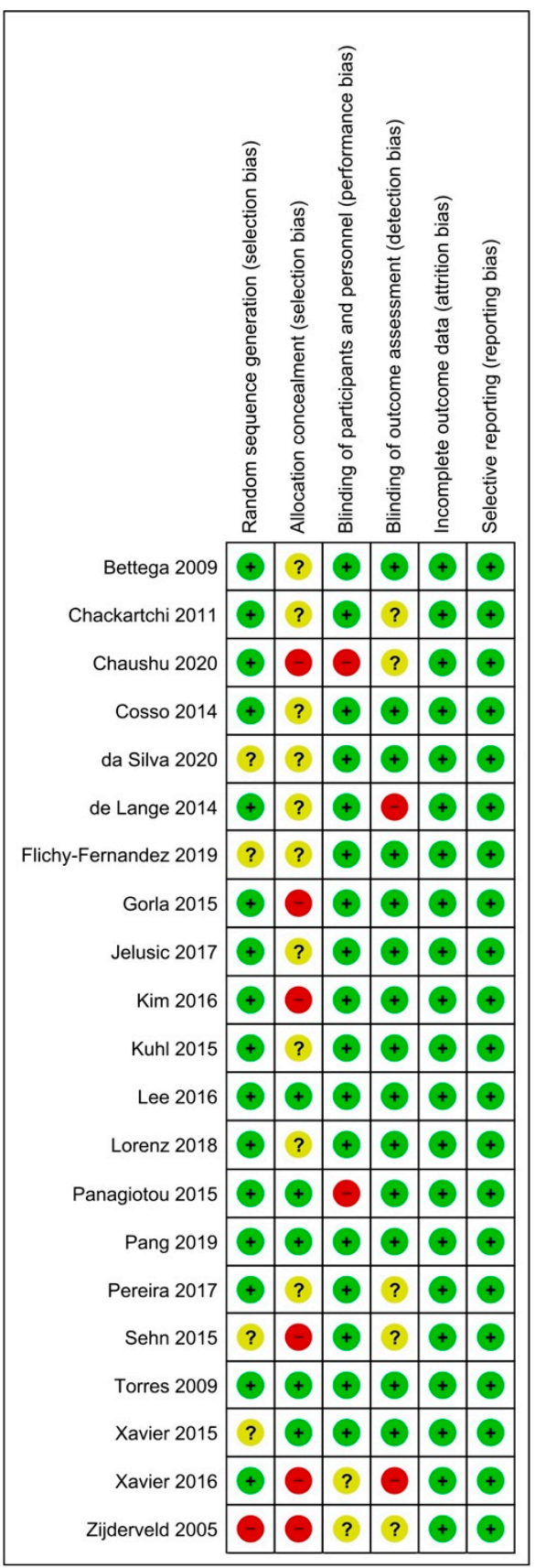

Figure 2. Risk of bias-Green low risk of bias, yellow unclear risk, red high risk of bias.

\subsection{Residual Bone Height and Post-Operative Vertical Change on New Bone Formation}

Thirteen studies presenting histomorphometric analyses, that mean residual (preoperative) bone height (RBH), and the postoperative bone height (PBH) for both test and control groups were included. In 10 studies, the biopsies were taken 6 months after sinus lift $[39,43-45,47,48,50,53,56,59]$ while in the remaining three articles, respectively, 9 months [41], 8 months [52], and between 6 and 9 months [40] from the first surgery.

In the first analysis, all the histomorphometric data of new bone formation percentage $(\mathrm{NBF} \%)$ values (i.e., mean values) were correlated with the respective mean $\mathrm{RBH}$. The hypothesis was that the NBF\% would increase when the RBH increased. The overall linear regression analysis showed a slight agreement with the hypothesis (Figure 3) with a regression coefficient $R^{2}=0.04$ and a slope of $2.11(95 \% C I=-2.19$ to 6.43$)$, meaning that NBF increases by $2.1 \%$ per each $\mathrm{mm}$ increase in residual bone height; therefore, the NBF was essentially independent of preoperative bone height. In other words, the observed 
increase in new bone formation with the increasing RBH was not significant $(p=0.32)$. Figure 4 shows that this analysis had different variable trends for each biomaterial (i.e., $\mathrm{AG}$; $\mathrm{AP} ; \mathrm{AU} ; \mathrm{AU}+\mathrm{PC}$; and XG).

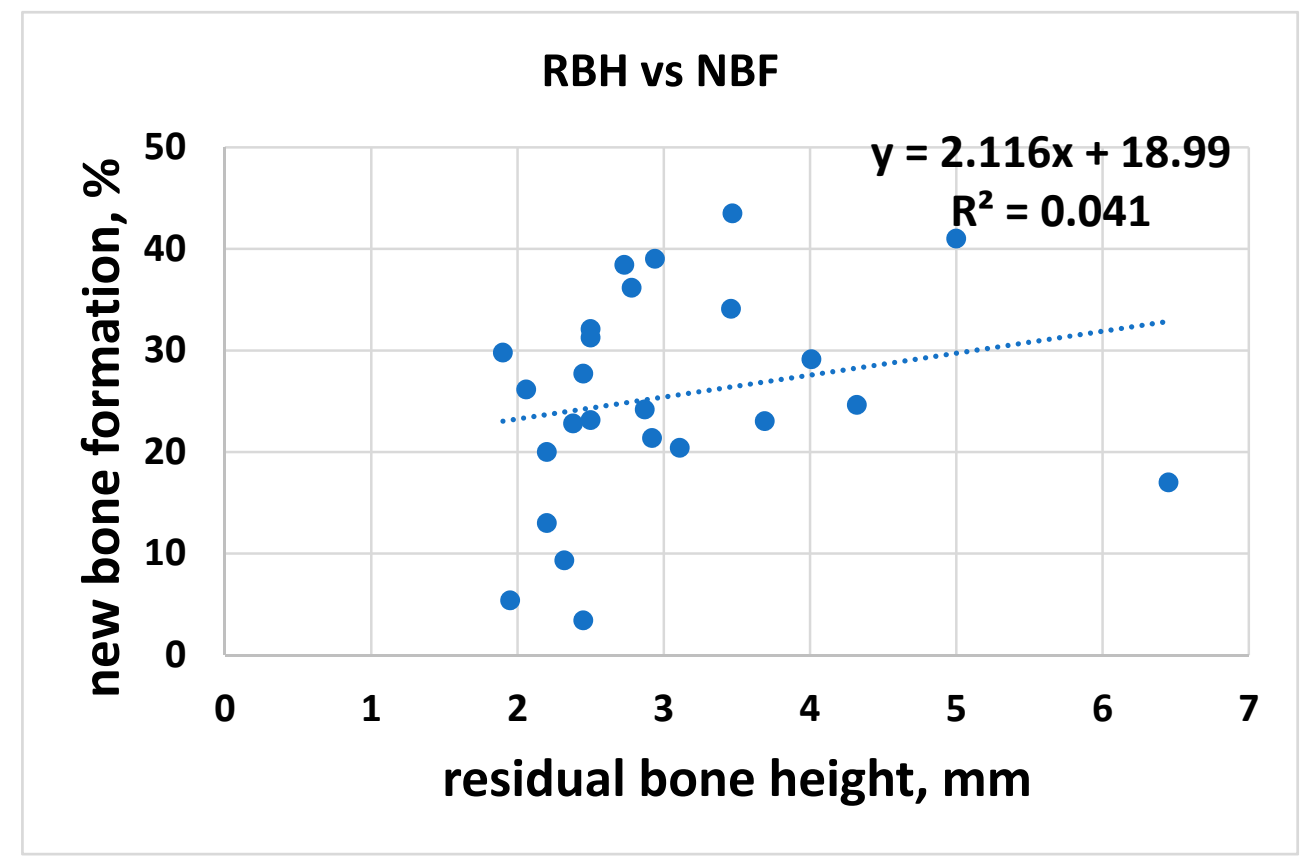

Figure 3. RBH and NBF.

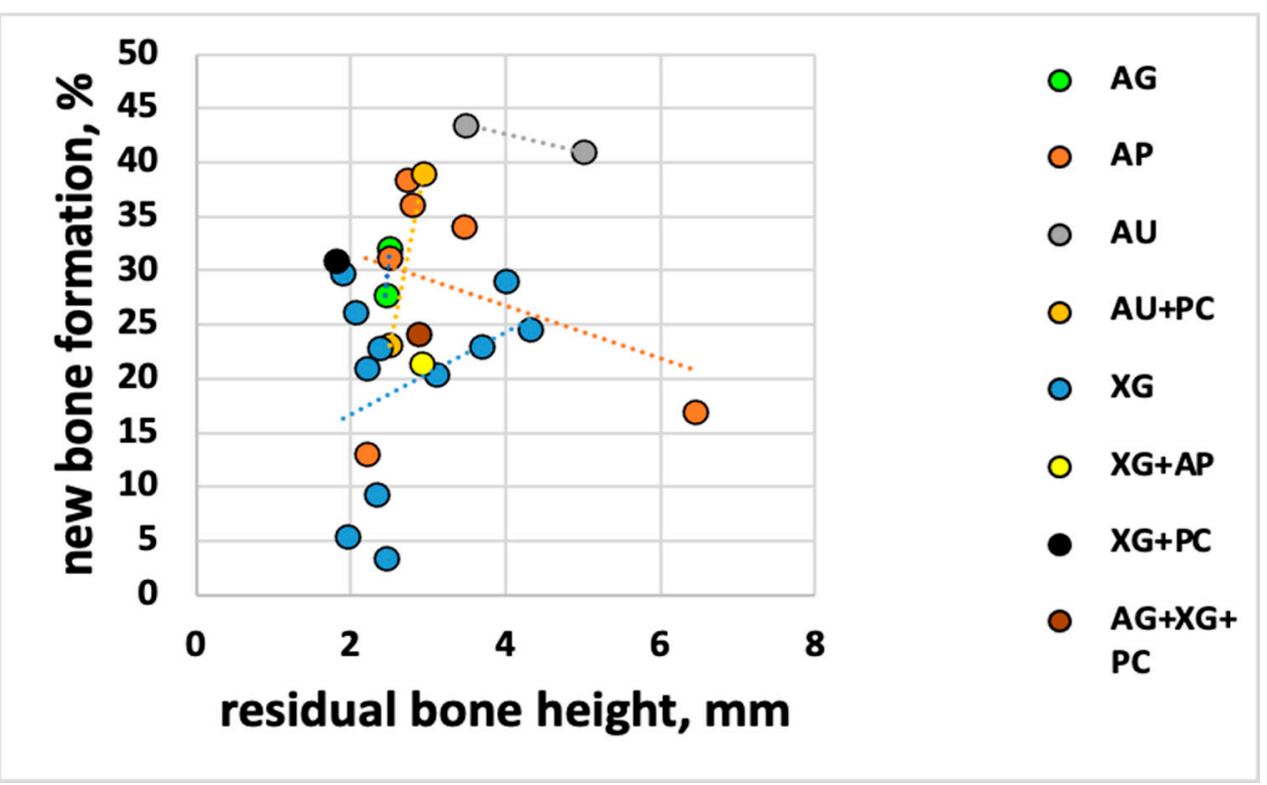

Figure 4. RBH and NBF for each biomaterial.

In the second analysis, the $\mathrm{NBF} \%$ was correlated with the postoperative height $(\mathrm{RBH}$ + vertical graft dimension) with the hypothesis that the higher the graft, the lower the new bone formation inside the graft. The overall linear regression analysis showed a tendency in agreement with the hypothesis (Figure 5) with a regression coefficient of $R^{2}=0.33$ and a slope of -1.56 ( $95 \%$ CI: -2.50 to -0.61$)$, meaning that NBF significantly decreased when postoperative vertical graft dimension increased. Per each $\mathrm{mm}$ of vertical height, NBF changed by about $1.6 \%$. The trend was highly significant $(p=0.0023)$. 


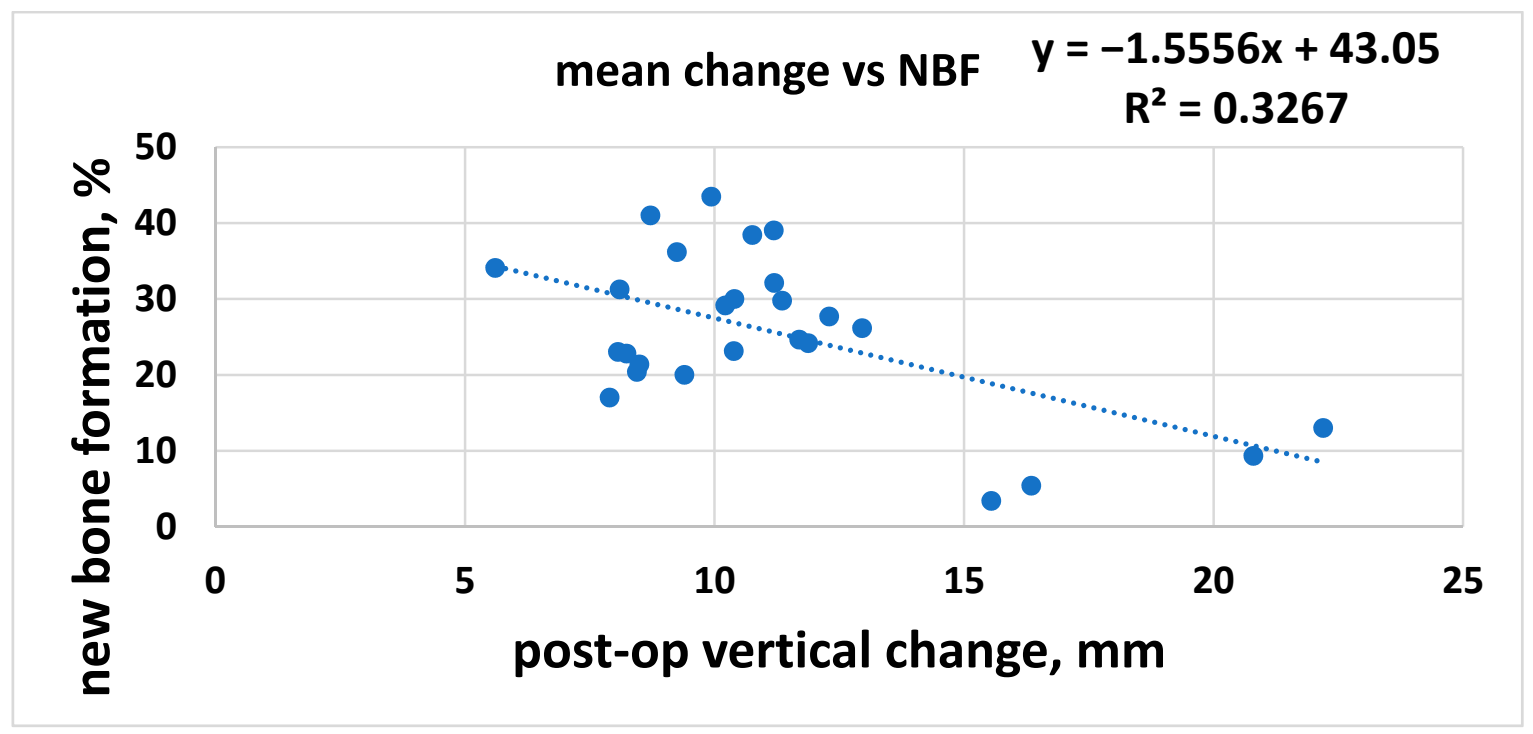

Figure 5. Post-operative vertical change and NBF.

It seemed interesting to investigate if the correlation was the same or different among the different materials. Since the number of samples per material was limited, a comparison could only be attempted between alloplasts $(n=6)$ and xenografts $(n=11)$ (Figure 6). The two linear regressions were almost overlapping, showing a similar tendency, with a regression coefficient even higher than the overall one $\left(R^{2}=0.37\right.$ for alloplasts and $R^{2}=0.48$ for xenografts).

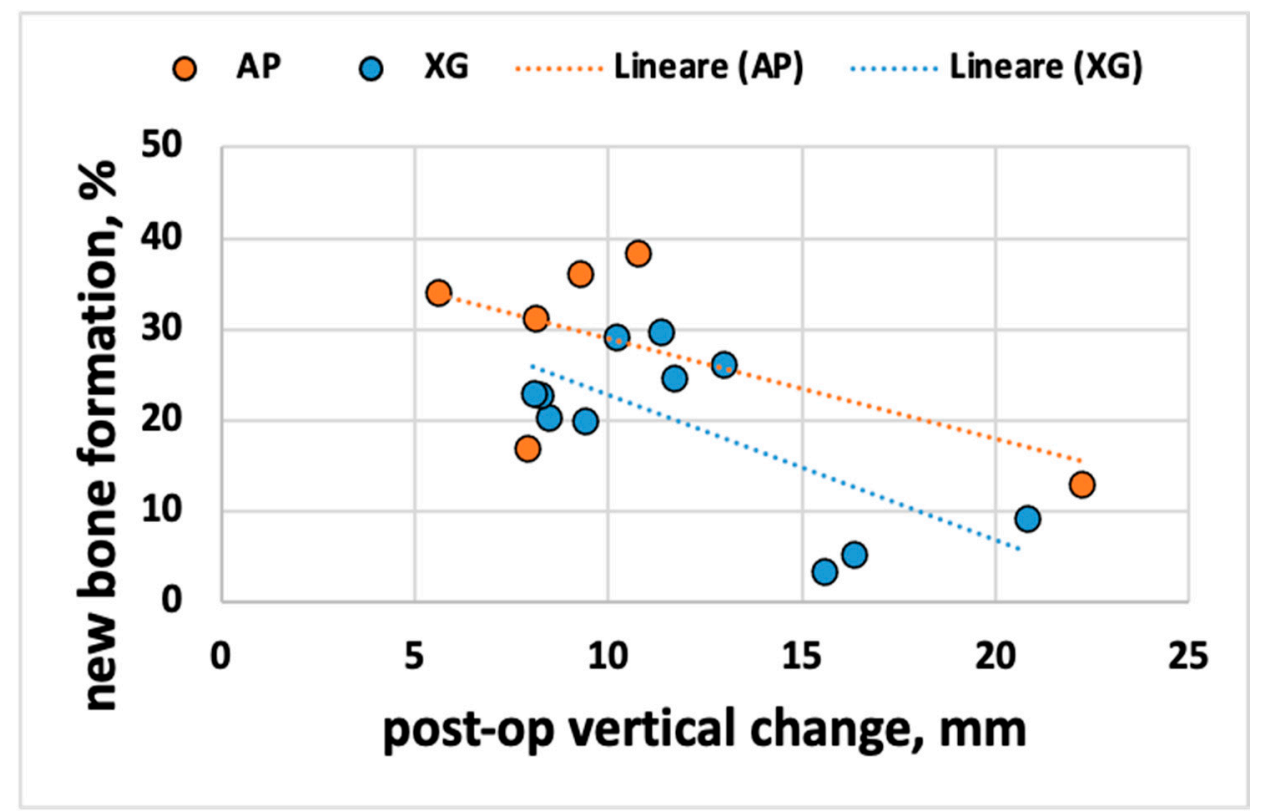

Figure 6. Post-operative vertical change and NBF for each biomaterial.

The postoperative bone height $(\mathrm{PBH})$, which was correlated to new bone formation, was obtained by adding the $\mathrm{RBH}$ and the graft vertical dimension itself. Given that the graft dimension was dependent on the amount of graft inserted by the operator at the surgical time, it was a variable that could be controlled to increase the expected new bone formation, as opposed to the residual bone height. 


\subsection{Shrinkage of Different Bone Substitutes}

Regarding graft volume changes, eleven RCTs were considered with a total of 302 sinuses. Graft volume was estimated using $\mathrm{CBCT}$, and volume change was calculated by subtracting the value at the 6-month follow-up from the baseline value. Data were grouped by grafting material. Five groups were considered including autogenous graft ( $\mathrm{AU}, \mathrm{n}=4)$, xenograft $(X G, n=5)$, alloplast (AP, $n=6)$, allograft $(A G, n=3)$, and autogenous + alloplast $(\mathrm{AU}+\mathrm{AP}, \mathrm{n}=2)$. The data of volume reduction in $\mathrm{mm}^{3}$ were normalized to the percentage of the reduction and dividing by the baseline values. Other grafts composed by combined materials $(A G+X G, X G+A P$, and $X G+A U)$ were not considered for comparison because each of them was investigated by a single study.

After 6 months, the material showing the lowest volume reduction was XG $(7.30 \pm 15.49 \%)$ while the one that resorbed most was AU $(41.71 \pm 12.63 \%)$. For the other biomaterials, a volumetric contraction of $27.82 \pm 15.58 \%$ was evaluated for the $\mathrm{AP}$, $30.23 \pm 1.61$ for the AG, and finally, $26.68 \pm 11.03 \%$ for AU + AP (Figure 7). Significant differences were only found between AU and XG $(p=0.009)$ and between AG and XG $(p=0.048)$ (Supplementary Table S3). An unpaired $t$-test was used for comparison. Other comparisons did not show significant differences.

\section{6-month graft resorption}
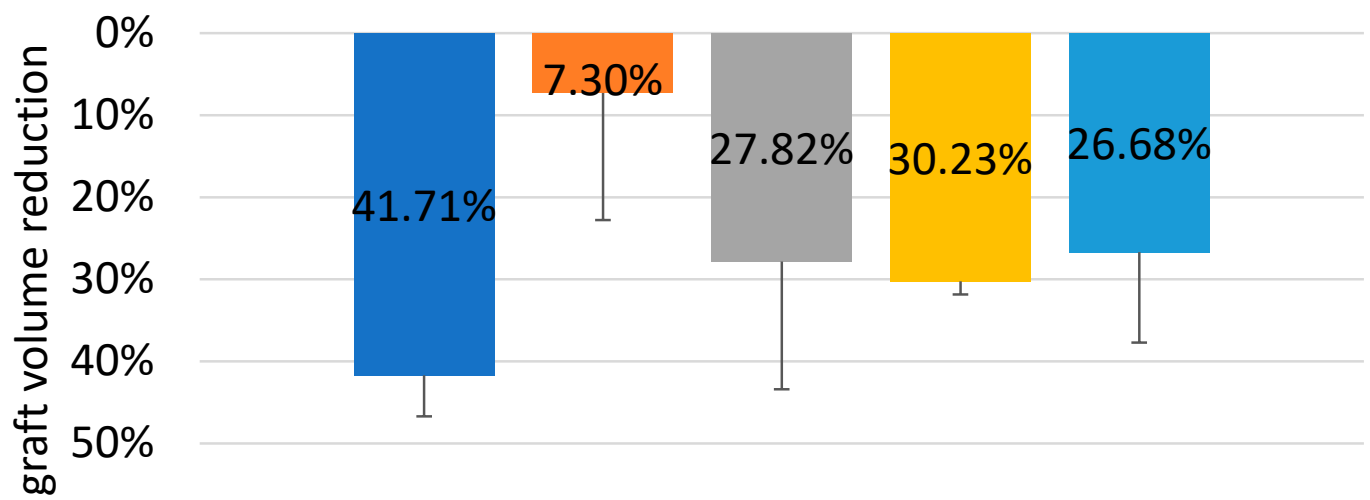

\section{$\square A U \square X G \square A P \square A G \square A U+A P$}

Figure 7. Percentage reduction for each biomaterial.

\subsection{Implant Survival}

From the analysis of the data extrapolated from the articles, only 10 implants, among 620 inserted, failed: three of those were placed in sinuses grafted with AG [55,57], three in sinus with AP [44,47,51], and three with XG [43,51]. The RCT of Flichy-Fernández et al. [45] reported the failure of one implant without, however, specifying in which group it occurred, and so it wasn't considered (Supplementary Tables S4 and S5).

\section{Post-Operative Complications}

Post-operative complications were not reported in five articles [42,45,46,51,56]. In nine studies, no unexpected events were observed, both in the surgical phases and in the postoperative course $[39,41,44,48,53-55,57,58]$.

Da Silva et al. [43] found four intraoperative perforations of the Schneiderian membrane with one of them occurring in a site grafted with Bio-Oss while the remaining three in the group were treated with Lumina-Bone Porous. The study by Jelusic et al. [47] detected the highest number of postoperative complications including five membrane perforations in the group treated with $\beta$-TCP and eight in the one treated with an alloplastic graft composed of $60 \%$ HA and $40 \% \beta$-TCP. Lee et al. [50], in addition to a perforation of the Schneiderian membrane of $10 \mathrm{~mm}$ in diameter that occurred in the group treated with DPBM, reported the appearance of extensive but temporary postoperative swelling in a site 
treated with DBBM, mainly due to patient negligence. Panagiotou et al. [52] reported the perforation of the Schneiderian membrane in two sites among those treated with Bio-Oss, while de Lange et al. found the same intraoperative complication in four of the sites grafted with AU and in two of those treated with AP [44]. Kuhl et al. [49] detected two perforations, one in the AP group and one in AP + AU.

In the split-mouth study by Chackartchi et al. [40], a patient had a bilateral postoperative infection involving both sinuses in comparison, respectively treated with XG having small $(0.25-1 \mathrm{~mm})$ and large $(1-2 \mathrm{~mm})$ size particles. In the RCT by Pereira et al. [54], a similar situation affected one patient belonging to the AP + AU group. These complications were resolved by administering antibiotic therapy.

\section{Discussion}

The aim of the present systematic review based on RCTs had been to investigate if there was an effect of residual bone height $(\mathrm{RBH})$ and vertical bone gain on new bone formation (NBF) as well as the shrinkage of the graft when using different biomaterials.

Graft volumetric shrinkage occurring after SLs using different biomaterials [46,54,60,61] influenced implant placement in two-stage lateral sinus lifts and could impact implant survival over time [62]. Furthermore, while complete resorption and replacement of the graft by a new bone formation is desirable, in some cases, a long-lasting scaffold was crucial to support osteointegrated implants [59]. Regarding the AU reabsorption, a recent meta-analysis by Starch-Jensen et al. [63] and a systematic review by Shanbhag et al. [64] confirmed our results. Unfortunately, in the present work, no meta-analysis of graft shrinkage could be performed as there were no more than two studies for each type of comparison between materials. Xenografts show a very slow resorption pattern $[26,28,29]$. This agrees with data obtained from this review and with those reported by Mazzocco et al. (7\%, at 8 months, ranging from $-29 \%$ to $18 \%$, for the delayed implant placement subgroup; and $13 \%$, at 8 months, ranging from $-24 \%$ to $-3 \%$, for the simultaneous implant placement subgroup) [65], and by Gutekin et al. (8.14 $\pm 3.76 \%$, at 6 months) [66]. Higher resorption values were instead reported after 6 months using deproteinized bovine bone by Salem et al. in a prospective randomized clinical pilot study $(23.8 \% \pm 15.9 \%)$ [67] and by Zhang et al. in a cohort study (22.7\%) [62].

The resorption rate of $\mathrm{AP}, \mathrm{AG}$, and $\mathrm{AU}+\mathrm{AP}$ indicated that greater graft stability may be achieved using bone substitutes or a composite graft, which then added AP to the patient's bone, compared to using AU alone. Similar conclusions were drawn by Shanbhag et al. in their review, which further stipulated that neither two-stage implant placements nor survival rates of simultaneously placed implants were affected by graft volume reductions [64].

Some authors suggested that the amount of new bone formation (\%) was a reliable parameter of bone graft performance since the greater that the quality of the newly formed bone was, the greater the BIC (bone-implant contact) will be, and, eventually, the implant survival [35]. Several reviews agreed, considering AU the gold standard in terms of new bone formation [21,34,35]. In particular, Al-Moraissi et al. recommended the use of only AU if the implant rehabilitation was planned within 6 months [21]; however, while Handschel et al. agreed, they suggested a similar course if the functional loading was expected within 9 months of sinus lift [68].

The NBF, as well as the material used in the sinus lift, may also be affected by sinus morphology and dimension; reduced osteogenic potential occurs in larger sinus cavities where more time is required to obtain adequate bone formation because of the greater distance between the sinus walls and the augmented region $[69,70]$. In narrow sinuses, it is more likely to achieve a better sinus membrane reflection as well as intimate contact between grafting material and sinus walls during transcrestal sinus floor elevation [70]. Considering that bone formation arises from the peripheral bony walls toward the centre of the graft [70], as we have seen in post-extraction socket healing, delayed or scarce graft maturation could occur if the preoperative amount of residual bone is minimal. Similarly, 
Corbella et al. hypothesized that if the sinus floor had only a thin layer of cortical bone, a lower percentage of NBF was to be expected, as compared to less atrophic cases in which the additional presence of cancellous bone could guarantee better regeneration potential [34]. Since the regenerative potential starts from the residual bone, NBF may also be affected by the harvesting technique and by the vertical gradient of graft consolidation in the collected specimens [71]. Beck et al., analysing histological thin-ground sections, demonstrated that NBF decreased with increasing distance from the residual sinus floor since the residual graft encapsulated by fibrous tissue had remained in the apical part of the augmented area [71].

Our results, revealing that residual bone height was not a remarkable factor affecting graft maturation, are in accordance with those reported by previous histomorphometric studies analysing biopsies retrieved 6 months after lateral sinus lift had been performed with XG [72] and AP [73]. Pignaton et al. [74] also confirmed that both RBH and sinus width were not influencing factors on new bone formation 8 months after lateral sinus lift with anorganic bovine bone.

Kühl et al. considered overaugmentation preferential in two-stage sinus lifts to compensate for expected graft volumetric reduction at the time of implant placement [75]. On the contrary, our results seemed to suggest that excessive vertical augmentations immediately after sinus floor elevation could lead to lower NBF at the time of the second surgery, even if a shrinkage of the material was always present.

Regarding the correlation between PBH and NBF, further studies are needed to investigate these hypotheses further and to understand the clinical significance of reducing the graft size in order to increase the NBF.

It has long been shown that NBF occurs in the maxillary sinus via sinus mucosa lifting without using any graft type [76-78], supporting the thesis of the osteogenic capability of the Schneiderian membrane. Although the debate is ongoing, this hypothesis has been confirmed by in vivo and in vitro studies $[79,80]$ that also demonstrated the presence of mesenchymal progenitor cells and cells committed to the osteogenic lineage in the membrane itself $[81,82]$. The obtained results suggested that a lower Schneiderian membrane elevation may be sufficient to trigger its osteogenic potential efficiently, as compared to grafting a greater amount of biomaterial, which would be counterproductive. Similarly, Beck et al. also concluded that a large augmentation height, particularly in the molar region, would not promote high NBF in an apical area within the grafted region [71].

One of the limits of the present review is the great variability of sinus morphology as sinus dimensions can influence the percentage of new bone formation, as has been shown by Stacchi et al. [83].

In addition, these conclusions could not be confirmed or denied as the current literature lacks RCTs, reviews, and meta-analyses assessing the correlation between vertical bone gain and histomorphometric outcomes.

\section{Conclusions}

Within the limits of the present systematic review, the following conclusions could be drawn:

Six months after lateral sinus lift, the material showing the lower volume reduction was the XG while the one that resorbed most was the $\mathrm{AU}$, according to the current literature.

Since the analysis of the correlation between NBF and RBH had revealed a nonsignificant increase in new bone formation when residual bone height increased, NBF is essentially independent of preoperative bone height.

NBF significantly decreased when postoperative vertical graft dimension increased, supporting the hypothesis that the higher the graft height, the lower the new bone formation within it. Therefore, at surgical time, the operators should carefully control the amount of grafted biomaterial applied to optimize the expected NBF.

Supplementary Materials: The following are available online at https: / www.mdpi.com/article / $10.3390 /$ jcm10214996/s1, Table S1: List of the excluded studies with the main reason for exclusion, 
Table S2: Main characteristics of the included studies, Table S3: P-values of the comparisons among groups, Table S4: Main characteristics of the included studies for volumetric changes, Table S5: Main characteristics of the included studies for histomorphometric and linear analisys.

Author Contributions: Conceptualization, P.P. and M.D.F.; methodology, M.D.F.; software, S.K.; data curation, L.M. and G.G.; writing-original draft preparation, P.P. and M.M.; writing-review and editing, P.P. and L.C. All authors have read and agreed to the published version of the manuscript.

Funding: This research received no external funding.

Institutional Review Board Statement: Not applicable.

Informed Consent Statement: Not applicable.

Data Availability Statement: Data available on request.

Conflicts of Interest: The authors declare no conflict of interest.

\section{References}

1. Gerken, U.; Esser, F.; Mohlhenrich, S.C.; Bartella, A.K.; Holzle, F.; Fischer, H.; Raith, S.; Steiner, T. Objective computerised assessment of residual ridge resorption in the human maxilla and maxillary sinus pneumatisation. Clin. Oral Investig. 2020, 24, 3223-3235. [CrossRef]

2. Mohan, N.; Wolf, J.; Dym, H. Maxillary sinus augmentation. Dent. Clin. N. Am. 2015, 59, 375-388. [CrossRef]

3. Tete, S.; Vinci, R.; Zizzari, V.L.; Zara, S.; La Scala, V.; Cataldi, A.; Gherlone, E.; Piattelli, A. Maxillary sinus augmentation procedures through equine-derived biomaterial or calvaria autologous bone: Immunohistochemical evaluation of OPG/RANKL in humans. Eur. J. Histochem. 2013, 57, e10. [CrossRef] [PubMed]

4. Att, W.; Bernhart, J.; Strub, J.R. Fixed rehabilitation of the edentulous maxilla: Possibilities and clinical outcome. J. Oral Maxillofac. Surg. 2009, 67, 60-73. [CrossRef] [PubMed]

5. Gallucci, G.O.; Avrampou, M.; Taylor, J.C.; Elpers, J.; Thalji, G.; Cooper, L.F. Maxillary Implant-Supported Fixed Prosthesis: A Survey of Reviews and Key Variables for Treatment Planning. Int. J. Oral Maxillofac. Implants 2016, 31, s192-s197. [CrossRef]

6. Baldi, D.; Menini, M.; Pera, F.; Ravera, G.; Pera, P. Sinus floor elevation using osteotomes or piezoelectric surgery. Int. J. Oral Maxillofac. Surg. 2011, 40, 497-503. [CrossRef]

7. Stacchi, C.; Spinato, S.; Lombardi, T.; Bernardello, F.; Bertoldi, C.; Zaffe, D.; Nevins, M. Minimally Invasive Management of Implant-Supported Rehabilitation in the Posterior Maxilla, Part II. Surgical Techniques and Decision Tree. Int. J. Periodontics Restor. Dent. 2020, 40, e95-e102. [CrossRef]

8. Tatum, H., Jr. Maxillary and sinus implant reconstructions. Dent. Clin. N. Am. 1986, 30, 207-229.

9. Boyne, P.J.; James, R.A. Grafting of the maxillary sinus floor with autogenous marrow and bone. J. Oral Surg. 1980, 38, 613-616. [PubMed]

10. Stacchi, C.; Andolsek, F.; Berton, F.; Perinetti, G.; Navarra, C.O.; di Lenarda, R. Intraoperative Complications During Sinus Floor Elevation with Lateral Approach: A Systematic Review. Int. J. Oral Maxillofac. Implants 2017, 32, e107-e118. [CrossRef] [PubMed]

11. Stacchi, C.; Vercellotti, T.; Toschetti, A.; Speroni, S.; Salgarello, S.; di Lenarda, R. Intraoperative complications during sinus floor elevation using two different ultrasonic approaches: A two-center, randomized, controlled clinical trial. Clin. Implant Dent. Relat. Res. 2015, 17, e117-e125. [CrossRef] [PubMed]

12. Ravida, A.; Wang, I.C.; Barootchi, S.; Askar, H.; Tavelli, L.; Gargallo-Albiol, J.; Wang, H.L. Meta-analysis of randomized clinical trials comparing clinical and patient-reported outcomes between extra-short $(\leq 6 \mathrm{~mm})$ and longer $(\geq 10 \mathrm{~mm}) \mathrm{implants}$. J. Clin. Periodontol. 2019, 46, 118-142. [CrossRef]

13. Iezzi, G.; Perrotti, V.; Felice, P.; Barausse, C.; Piattelli, A.; del Fabbro, M. Are <7-mm long implants in native bone as effective as longer implants in augmented bone for the rehabilitation of posterior atrophic jaws? A systematic review and meta-analysis. Clin. Implant. Dent. Relat. Res. 2020, 22, 552-566. [CrossRef]

14. Pera, P.; Menini, M.; Pesce, P.; Bevilacqua, M.; Pera, F.; Tealdo, T. Immediate Versus Delayed Loading of Dental Implants Supporting Fixed Full-Arch Maxillary Prostheses: A 10-year Follow-up Report. Int. J. Prosthodont. 2019, 32, 27-31. [CrossRef] [PubMed]

15. Menini, M.; Signori, A.; Tealdo, T.; Bevilacqua, M.; Pera, F.; Ravera, G.; Pera, P. Tilted implants in the immediate loading rehabilitation of the maxilla: A systematic review. J. Dent. Res. 2012, 91, 821-827. [CrossRef] [PubMed]

16. Jensen, O.T.; Shulman, L.B.; Block, M.S.; Iacono, V.J. Report of the Sinus Consensus Conference of 1996. Int. J. Oral Maxillofac. Implants 1998, 13, 11-45. [PubMed]

17. Cabezas-Mojon, J.; Barona-Dorado, C.; Gomez-Moreno, G.; Fernandez-Caliz, F.; Martinez-Gonzalez, J.M. Meta-analytic study of implant survival following sinus augmentation. Med. Oral Patol. Oral Cir. Bucal 2012, 17, e135-e139. [CrossRef]

18. Del Fabbro, M.; Testori, T.; Francetti, L.; Weinstein, R. Systematic review of survival rates for implants placed in the grafted maxillary sinus. Int. J. Periodontics Rest. Dent. 2004, 24, 565-577. [CrossRef]

19. Pjetursson, B.E.; Tan, W.C.; Zwahlen, M.; Lang, N.P. A systematic review of the success of sinus floor elevation and survival of implants inserted in combination with sinus floor elevation. J. Clin. Periodontol. 2008, 35, 216-240. [CrossRef] 
20. Del Fabbro, M.; Wallace, S.S.; Testori, T. Long-term implant survival in the grafted maxillary sinus: A systematic review. Int. J. Periodontics Rest. Dent. 2013, 33, 773-783. [CrossRef] [PubMed]

21. Al-Moraissi, E.A.; Alkhutari, A.S.; Abotaleb, B.; Altairi, N.H.; del Fabbro, M. Do osteoconductive bone substitutes result in similar bone regeneration for maxillary sinus augmentation when compared to osteogenic and osteoinductive bone grafts? A systematic review and frequentist network meta-analysis. Int. J. Oral Maxillofac. Surg. 2020, 49, 107-120. [CrossRef] [PubMed]

22. Albrektsson, T.; Johansson, C. Osteoinduction, osteoconduction and osseointegration. Eur. Spine J. 2001, 10, S96-S101. [CrossRef]

23. Danesh-Sani, S.A.; Loomer, P.M.; Wallace, S.S. A comprehensive clinical review of maxillary sinus floor elevation: Anatomy, techniques, biomaterials and complications. Br. J. Oral Maxillofac. Surg. 2016, 54, 724-730. [CrossRef]

24. Browaeys, H.; Bouvry, P.; De Bruyn, H. A literature review on biomaterials in sinus augmentation procedures. Clin. Implant Dent. Relat. Res. 2007, 9, 166-177. [CrossRef]

25. Froum, S.J.; Tarnow, D.P.; Wallace, S.S.; Rohrer, M.D.; Cho, S.C. Sinus floor elevation using anorganic bovine bone matrix (OsteoGraf/N) with and without autogenous bone: A clinical, histologic, radiographic, and histomorphometric analysis-Part 2 of an ongoing prospective study. Int. J. Periodontics Rest. Dent. 1998, 18, 528-543.

26. Hallman, M.; Sennerby, L.; Lundgren, S. A clinical and histologic evaluation of implant integration in the posterior maxilla after sinus floor augmentation with autogenous bone, bovine hydroxyapatite, or a 20:80 mixture. Int. J. Oral Maxillofac. Implants 2002, 17, 635-643. [PubMed]

27. Merli, M.; Moscatelli, M.; Mariotti, G.; Rotundo, R.; Nieri, M. Autogenous bone versus deproteinised bovine bone matrix in 1-stage lateral sinus floor elevation in the severely atrophied maxilla: A randomised controlled trial. Eur. J. Oral Implantol. 2013, 6, 27-37.

28. Hallman, M.; Lundgren, S.; Sennerby, L. Histologic analysis of clinical biopsies taken 6 months and 3 years after maxillary sinus floor augmentation with $80 \%$ bovine hydroxyapatite and $20 \%$ autogenous bone mixed with fibrin glue. Clin. Implant Dent. Relat. Res. 2001, 3, 87-96. [CrossRef]

29. Mordenfeld, A.; Hallman, M.; Johansson, C.B.; Albrektsson, T. Histological and histomorphometrical analyses of biopsies harvested 11 years after maxillary sinus floor augmentation with deproteinized bovine and autogenous bone. Clin. Oral Implants Res. 2010, 21, 961-970. [CrossRef] [PubMed]

30. Kolerman, R.; Nissan, J.; Rahmanov, M.; Vered, H.; Cohen, O.; Tal, H. Comparison between mineralized cancellous bone allograft and an alloplast material for sinus augmentation: A split mouth histomorphometric study. Clin. Implant Dent. Relat. Res. 2017, 19, 812-820. [CrossRef] [PubMed]

31. Precheur, H.V. Bone graft materials. Dent. Clin. N. Am. 2007, 51, 729-746. [CrossRef] [PubMed]

32. Baldi, D.; Pesce, P.; Musante, B.; Pera, F.; Fulcheri, E.; Romano, F.; Menini, M. Radiological and Histomorphometric Outcomes of Homologous Bone Graft in Postextractive Implant Sites: A 6-Year Retrospective Analysis. Implant Dent. 2019, 28 , $472-477$. [CrossRef]

33. Schwartz, Z.; Somers, A.; Mellonig, J.T.; Carnes, D.L., Jr.; Dean, D.D.; Cochran, D.L.; Boyan, B.D. Ability of commercial demineralized freeze-dried bone allograft to induce new bone formation is dependent on donor age but not gender. J. Periodontol. 1998, 69, 470-478. [CrossRef]

34. Corbella, S.; Taschieri, S.; Weinstein, R.; del Fabbro, M. Histomorphometric outcomes after lateral sinus floor elevation procedure: A systematic review of the literature and meta-analysis. Clin. Oral Implants Res. 2016, 27, 1106-1122. [CrossRef]

35. Danesh-Sani, S.A.; Engebretson, S.P.; Janal, M.N. Histomorphometric results of different grafting materials and effect of healing time on bone maturation after sinus floor augmentation: A systematic review and meta-analysis. J. Periodontal. Res. 2017, 52, 301-312. [CrossRef]

36. Stumbras, A.; Krukis, M.M.; Januzis, G.; Juodzbalys, G. Regenerative bone potential after sinus floor elevation using various bone graft materials: A systematic review. Quintessence Int. 2019, 50, 548-558. [CrossRef]

37. Trimmel, B.; Gede, N.; Hegyi, P.; Szakacs, Z.; Mezey, G.A.; Varga, E.; Kivovics, M.; Hanak, L.; Rumbus, Z.; Szabo, G. Relative performance of various biomaterials used for maxillary sinus augmentation: A Bayesian network meta-analysis. Clin. Oral Implants Res. 2021, 32, 135-153. [CrossRef]

38. Higgins, J.P.T.; Green, S. Cochrane Collaboration. Cochrane Handbook for Systematic Reviews of Interventions; Wiley-Blackwell: Chichester, UK; Hoboken, NJ, USA, 2008; p. xxi. 649p.

39. Bettega, G.; Brun, J.P.; Boutonnat, J.; Cracowski, J.L.; Quesada, J.L.; Hegelhofer, H.; Drillat, P.; Richard, M.J. Autologous platelet concentrates for bone graft enhancement in sinus lift procedure. Transfusion 2009, 49, 779-785. [CrossRef] [PubMed]

40. Chackartchi, T.; Iezzi, G.; Goldstein, M.; Klinger, A.; Soskolne, A.; Piattelli, A.; Shapira, L. Sinus floor augmentation using large (1$2 \mathrm{~mm}$ ) or small $(0.25-1 \mathrm{~mm})$ bovine bone mineral particles: A prospective, intra-individual controlled clinical, micro-computerized tomography and histomorphometric study. Clin. Oral Implants Res. 2011, 22, 473-480. [CrossRef] [PubMed]

41. Chaushu, L.; Chaushu, G.; Kolerman, R.; Vered, M.; Naishols, S.; Nissan, J. Histomorphometrical Assessment of Sinus Augmentation Using Allograft (Particles or Block) and Simultaneous Implant Placement. Sci. Rep. 2020, 10, 9046. [CrossRef] [PubMed]

42. Cosso, M.G.; de Brito, R.B., Jr.; Piattelli, A.; Shibli, J.A.; Zenobio, E.G. Volumetric dimensional changes of autogenous bone and the mixture of hydroxyapatite and autogenous bone graft in humans maxillary sinus augmentation. A multislice tomographic study. Clin. Oral Implants Res. 2014, 25, 1251-1256. [CrossRef] [PubMed] 
43. Da Silva, H.F.; Goulart, D.R.; Sverzut, A.T.; Olate, S.; de Moraes, M. Comparison of two anorganic bovine bone in maxillary sinus lift: A split-mouth study with clinical, radiographical, and histomorphometrical analysis. Int. J. Implant Dent. $2020,6,17$. [CrossRef]

44. De Lange, G.L.; Overman, J.R.; Farre-Guasch, E.; Korstjens, C.M.; Hartman, B.; Langenbach, G.E.; van Duin, M.A.; Klein-Nulend, J. A histomorphometric and micro-computed tomography study of bone regeneration in the maxillary sinus comparing biphasic calcium phosphate and deproteinized cancellous bovine bone in a human split-mouth model. Oral Surg. Oral Med. Oral Pathol. Oral Radiol. 2014, 117, 8-22. [CrossRef]

45. Flichy-Fernandez, A.J.; Blaya-Tarraga, J.A.; O’Valle, F.; Padial-Molina, M.; Penarrocha-Diago, M.; Galindo-Moreno, P. Sinus floor elevation using particulate PLGA-coated biphasic calcium phosphate bone graft substitutes: A prospective histological and radiological study. Clin. Implant Dent. Relat. Res. 2019, 21, 895-902. [CrossRef] [PubMed]

46. Gorla, L.F.; Spin-Neto, R.; Boos, F.B.; Pereira Rdos, S.; Garcia-Junior, I.R.; Hochuli-Vieira, E. Use of autogenous bone and beta-tricalcium phosphate in maxillary sinus lifting: A prospective, randomized, volumetric computed tomography study. Int. J. Oral Maxillofac. Surg. 2015, 44, 1486-1491. [CrossRef] [PubMed]

47. Jelusic, D.; Zirk, M.L.; Fienitz, T.; Plancak, D.; Puhar, I.; Rothamel, D. Monophasic ss-TCP vs. biphasic HA/ss-TCP in two-stage sinus floor augmentation procedures-a prospective randomized clinical trial. Clin. Oral Implants Res. 2017, 28, e175-e183. [CrossRef]

48. Kim, E.S.; Kang, J.Y.; Kim, J.J.; Kim, K.W.; Lee, E.Y. Space maintenance in autogenous fresh demineralized tooth blocks with platelet-rich plasma for maxillary sinus bone formation: A prospective study. SpringerPlus 2016, 5, 274. [CrossRef]

49. Kuhl, S.; Payer, M.; Kirmeier, R.; Wildburger, A.; Acham, S.; Jakse, N. The influence of particulated autogenous bone on the early volume stability of maxillary sinus grafts with biphasic calcium phosphate: A randomized clinical trial. Clin. Implant Dent. Relat. Res. 2015, 17, 173-178. [CrossRef] [PubMed]

50. Lee, J.S.; Shin, H.K.; Yun, J.H.; Cho, K.S. Randomized Clinical Trial of Maxillary Sinus Grafting using Deproteinized Porcine and Bovine Bone Mineral. Clin. Implant Dent. Relat. Res. 2017, 19, 140-150. [CrossRef] [PubMed]

51. Lorenz, J.; Korzinskas, T.; Chia, P.; Maawi, S.A.; Eichler, K.; Sader, R.A.; Ghanaati, S. Do Clinical and Radiological Assessments Contribute to the Understanding of Biomaterials? Results from a Prospective Randomized Sinus Augmentation Split-Mouth Trial. J. Oral Implantol. 2018, 44, 62-69. [CrossRef]

52. Panagiotou, D.; Ozkan Karaca, E.; Dirikan Ipci, S.; Cakar, G.; Olgac, V.; Yilmaz, S. Comparison of two different xenografts in bilateral sinus augmentation: Radiographic and histologic findings. Quintessence Int. 2015, 46, 611-619. [CrossRef]

53. Pang, K.M.; Lee, J.K.; Choi, S.H.; Kim, Y.K.; Kim, B.J.; Lee, J.H. Maxillary Sinus Augmentation With Calcium Phosphate Double-Coated Anorganic Bovine Bone: Comparative Multicenter Randomized Clinical Trial With Histological and Radiographic Evaluation. Implant Dent. 2019, 28, 39-45. [CrossRef] [PubMed]

54. Pereira, R.S.; Menezes, J.D.; Bonardi, J.P.; Griza, G.L.; Okamoto, R.; Hochuli-Vieira, E. Comparative study of volumetric changes and trabecular microarchitecture in human maxillary sinus bone augmentation with bioactive glass and autogenous bone graft: A prospective and randomized assessment. Int. J. Oral Maxillofac. Surg. 2018, 47, 665-671. [CrossRef]

55. Sehn, F.P.; Dias, R.R.; de Santana Santos, T.; Silva, E.R.; Salata, L.A.; Chaushu, G.; Xavier, S.P. Fresh-frozen allografts combined with bovine bone mineral enhance bone formation in sinus augmentation. J. Biomater. Appl. 2015, 29, 1003-1013. [CrossRef] [PubMed]

56. Torres, J.; Tamimi, F.; Martinez, P.P.; Alkhraisat, M.H.; Linares, R.; Hernandez, G.; Torres-Macho, J.; Lopez-Cabarcos, E. Effect of platelet-rich plasma on sinus lifting: A randomized-controlled clinical trial. J. Clin. Periodontol. 2009, 36, 677-687. [CrossRef]

57. Xavier, S.P.; Santos Tde, S.; Sehn, F.P.; Silva, E.R.; Garcez-Filho Jde, A.; Martins-Filho, P.R. Maxillary sinus grafting with fresh frozen allograft versus bovine bone mineral: A tomographic and histological study. J. Craniomaxillofac. Surg. 2016, 44, 708-714. [CrossRef] [PubMed]

58. Xavier, S.P.; Silva, E.R.; Kahn, A.; Chaushu, L.; Chaushu, G. Maxillary Sinus Grafting with Autograft Versus Fresh-Frozen Allograft: A Split-Mouth Evaluation of Bone Volume Dynamics. Int. J. Oral Maxillofac. Implants 2015, 30, 1137-1142. [CrossRef] [PubMed]

59. Zijderveld, S.A.; Schulten, E.A.; Aartman, I.H.; ten Bruggenkate, C.M. Long-term changes in graft height after maxillary sinus floor elevation with different grafting materials: Radiographic evaluation with a minimum follow-up of 4.5 years. Clin. Oral Implants Res. 2009, 20, 691-700. [CrossRef]

60. Hatano, N.; Shimizu, Y.; Ooya, K. A clinical long-term radiographic evaluation of graft height changes after maxillary sinus floor augmentation with a 2:1 autogenous bone/xenograft mixture and simultaneous placement of dental implants. Clin. Oral Implants Res. 2004, 15, 339-345. [CrossRef]

61. Menezes, J.D.; Pereira, R.D.S.; Santos, A.M.S.; de Siqueira, N.B.; Boos-Lima, F.; Hochuli-Vieira, E. Three-dimensional volumetric changes of 5 different bone grafts in human maxillary sinuses reconstruction: A randomized clinical study. Oral Maxillofac. Surg. 2021, 1-7. [CrossRef]

62. Zhang, L.; Si, M.; Shi, J.; Yang, G.; Shi, Y. Evaluation of three-dimensional contraction of the volume of grafts after staged augmentation of the sinus floor, and an analysis of influential factors. Br. J. Oral Maxillofac. Surg. 2019, 57, 323-329. [CrossRef]

63. Starch-Jensen, T.; Deluiz, D.; Vitenson, J.; Bruun, N.H.; Tinoco, E.M.B. Maxillary Sinus Floor Augmentation with Autogenous Bone Graft Compared with a Composite Grafting Material or Bone Substitute Alone: A Systematic Review and Meta-Analysis Assessing Volumetric Stability of the Grafting Material. J. Oral Maxillofac. Res. 2021, 12, e1. [CrossRef] 
64. Shanbhag, S.; Shanbhag, V.; Stavropoulos, A. Volume changes of maxillary sinus augmentations over time: A systematic review. Int. J. Oral Maxillofac. Implants 2014, 29, 881-892. [CrossRef]

65. Mazzocco, F.; Lops, D.; Gobbato, L.; Lolato, A.; Romeo, E.; del Fabbro, M. Three-dimensional volume change of grafted bone in the maxillary sinus. Int. J. Oral Maxillofac. Implants 2014, 29, 178-184. [CrossRef]

66. Gultekin, B.A.; Cansiz, E.; Borahan, O.; Mangano, C.; Kolerman, R.; Mijiritsky, E.; Yalcin, S. Evaluation of Volumetric Changes of Augmented Maxillary Sinus With Different Bone Grafting Biomaterials. J. Craniofac. Surg. 2016, 27, e144-e148. [CrossRef] [PubMed]

67. Salem, D.; Alshihri, A.; Arguello, E.; Jung, R.E.; Mohmed, H.A.; Friedland, B. Volumetric Analysis of Allogenic and Xenogenic Bone Substitutes Used in Maxillary Sinus Augmentations Utilizing Cone Beam CT: A Prospective Randomized Pilot Study. Int. J. Oral Maxillofac. Implants 2019, 34, 920-926. [CrossRef] [PubMed]

68. Handschel, J.; Simonowska, M.; Naujoks, C.; Depprich, R.A.; Ommerborn, M.A.; Meyer, U.; Kubler, N.R. A histomorphometric meta-analysis of sinus elevation with various grafting materials. Head Face Med. 2009, 5, 12. [CrossRef] [PubMed]

69. Avila, G.; Wang, H.L.; Galindo-Moreno, P.; Misch, C.E.; Bagramian, R.A.; Rudek, I.; Benavides, E.; Moreno-Riestra, I.; Braun, T.; Neiva, R. The influence of the bucco-palatal distance on sinus augmentation outcomes. J. Periodontol. 2010, 81, 1041-1050. [CrossRef] [PubMed]

70. Kolerman, R.; Tal, H.; Moses, O. Histomorphometric analysis of newly formed bone after maxillary sinus floor augmentation using ground cortical bone allograft and internal collagen membrane. J. Periodontol. 2008, 79, 2104-2111. [CrossRef] [PubMed]

71. Beck, F.; Reich, K.M.; Lettner, S.; Heimel, P.; Tangl, S.; Redl, H.; Ulm, C. The vertical course of bone regeneration in maxillary sinus floor augmentations: A histomorphometric analysis of human biopsies. J. Periodontol. 2021, 92, 263-272. [CrossRef]

72. Taschieri, S.; Ofer, M.; Corbella, S.; Testori, T.; Dellavia, C.; Nemcovsky, C.; Canciani, E.; Francetti, L.; del Fabbro, M.; Tartaglia, G. The Influence of Residual Alveolar Bone Height on Graft Composition after Maxillary Sinus Augmentation Using Two Different Xenografts: A Histomorphometric Comparative Study. Materials 2020, 13, 5093. [CrossRef] [PubMed]

73. Avila-Ortiz, G.; Neiva, R.; Galindo-Moreno, P.; Rudek, I.; Benavides, E.; Wang, H.L. Analysis of the influence of residual alveolar bone height on sinus augmentation outcomes. Clin. Oral Implants Res. 2012, 23, 1082-1088. [CrossRef] [PubMed]

74. Pignaton, T.B.; Wenzel, A.; Ferreira, C.E.A.; Borges Martinelli, C.; Oliveira, G.; Marcantonio, E., Jr.; Spin-Neto, R. Influence of residual bone height and sinus width on the outcome of maxillary sinus bone augmentation using anorganic bovine bone. Clin. Oral Implants Res. 2019, 30, 315-323. [CrossRef]

75. Kuhl, S.; Payer, M.; Kirmeier, R.; Wildburger, A.; Wegscheider, W.; Jakse, N. The influence of bone marrow aspirates and concentrates on the early volume stability of maxillary sinus grafts with deproteinized bovine bone mineral—First results of a RCT. Clin. Oral Implants Res. 2014, 25, 221-225. [CrossRef]

76. Falah, M.; Sohn, D.S.; Srouji, S. Graftless sinus augmentation with simultaneous dental implant placement: Clinical results and biological perspectives. Int. J. Oral Maxillofac. Surg. 2016, 45, 1147-1153. [CrossRef]

77. Lundgren, S.; Andersson, S.; Gualini, F.; Sennerby, L. Bone reformation with sinus membrane elevation: A new surgical technique for maxillary sinus floor augmentation. Clin. Implant Dent. Relat. Res. 2004, 6, 165-173. [CrossRef]

78. Riben, C.; Thor, A. The Maxillary Sinus Membrane Elevation Procedure: Augmentation of Bone around Dental Implants without Grafts-A Review of a Surgical Technique. Int. J. Dent. 2012, 2012, 105483. [CrossRef] [PubMed]

79. Derjac-Arama, A.I.; Sarafoleanu, C.; Manea, C.M.; Nicolescu, M.I.; Vrapciu, A.D.; Rusu, M.C. Regenerative potential of human schneiderian membrane: Progenitor cells and epithelial-mesenchymal transition. Anat. Rec. 2015, 298, 2132-2140. [CrossRef]

80. Srouji, S.; Ben-David, D.; Lotan, R.; Riminucci, M.; Livne, E.; Bianco, P. The innate osteogenic potential of the maxillary sinus (Schneiderian) membrane: An ectopic tissue transplant model simulating sinus lifting. Int. J. Oral Maxillofac. Surg. 2010, 39, 793-801. [CrossRef]

81. Gruber, R.; Kandler, B.; Fuerst, G.; Fischer, M.B.; Watzek, G. Porcine sinus mucosa holds cells that respond to bone morphogenetic protein (BMP)-6 and BMP-7 with increased osteogenic differentiation in vitro. Clin. Oral Implants Res. 2004, 15, 575-580. [CrossRef]

82. Srouji, S.; Kizhner, T.; Ben David, D.; Riminucci, M.; Bianco, P.; Livne, E. The Schneiderian membrane contains osteoprogenitor cells: In vivo and in vitro study. Calcif. Tissue Int. 2009, 84, 138-145. [CrossRef] [PubMed]

83. Stacchi, C.; Lombardi, T.; Ottonelli, R.; Berton, F.; Perinetti, G.; Traini, T. New bone formation after transcrestal sinus floor elevation was influenced by sinus cavity dimensions: A prospective histologic and histomorphometric study. Clin. Oral Implants Res. 2018, 29, 465-479. [CrossRef] [PubMed] 